\title{
SOBRE PROJETOS EM MALHA: DO EDIFÍCIO À CIDADE
}

\author{
SOBRE LOS PROYECTOS DE MALLAS, DEL EDIFICIO A LA CIUDAD
}

\section{ABOUT MESH PROJECTS, FROM THE BUILDING TO THE CITY}

\section{MACEDO, ADILSON COSTA}

Professor Doutor, Faculdade de Arquitetura e Urbanismo da Universidade de São Paulo. Email: adilsoncm2@gmail.com

\section{RESUMO}

Edifícios e setores urbanos traçados em malha são um pretexto para repassar alguns conceitos que aguçaram a crítica ao Movimento Moderno nos anos 1960.0 grupo de arquitetos conhecido por Team $X$, idealizou projetos de maneira que os prédios de um mesmo conjunto fossem interligados, divergindo da vertente Moderna de colocar edifícios únicos em espaços ajardinados. Da autoria de arquitetos relacionados ao Team X, destaca-se o projeto vencedor do concurso internacional de anteprojetos para a Universidade Livre de Berlim que utilizou o princípio de malha ordenadora da área edificada e dos espaços livres. Desta referência tem início a trajetória deste autor, primeiro ligada às retículas para organizar o edifício como um bloco único, depois, graças a programas exigentes quanto à funcionalidade, veio a preocupação com os espaços gerados pelo movimento das pessoas e coisas, corredores para atravessar o prédio e corredores para distribuir a circulação no âmbito dos setores; conceitos que se estenderam depois para o estudo da forma e projeto da cidade. Mostram-se exemplos da possibilidade do uso das malhas por setores de um edifício, separados por corredores para pessoas e cargas, segundo o princípio de que 0 módulo para a organização dos espaços pode variar dentre os setores.

PALAVRAS-CHAVE: malha urbana; projeto do edifício; projeto urbano.

\section{RESUMEN}

Edifícios y sectores urbanos trazados en malla son un pretexto para transmitir algunos conceptos que agudizaron la crítica al Movimiento Moderno en la década de 1960. Aspecto moderno de colocar edificios singulares en espacios ajardinados. De la autoría de arquitectos afines al Team X, destaca el proyecto ganador del concurso internacional de anteproyectos de la Universidad Libre de Berlín, que utilizó el principio de cuadrí́cula de ordenamiento de la superficie edificada y los espacios abiertos. A partir de esta referencia comenzó la trayectoria conceptual de este autor, primero vinculado a las rejillas para organizar el edificio como un solo bloque, luego, gracias a programas exigentes en cuanto a funcionalidad, surgió la preocupación por los espacios generados por el movimiento de personas y cosas, pasillos para recorrer el edificio y corredores para distribuir la circulación dentro de los sectores; conceptos que se extendieron al estudio de la forma y diseño de la ciudad. Se muestran ejemplos de la posibilidad de utilizar mallas por sectores de un proyecto, separados por pasillos para personas y carga, según el principio de que el módulo para la organización de espacios puede variar entre sectores.

PALABRAS CLAVE: malla urbana; diseño de edifícios; diseño urbano.

\section{ABSTRACT}

Buildings and urban sectors traced in mesh are a pretext to pass on some concepts that sharpened criticism of the Modern Movement in the 1960s. The group of architects known as Team X, conceived projects so that the buildings of the same set were interconnected, diverging from the Modern aspect of placing unique buildings in landscaped spaces. Authored by architects related to Team $X$, the winning project of the international pre-project competition for the Free University of Berlin stands out, which used the principle of ordering grid of the built-up area and open spaces. From this reference began the trajectory of this author, first linked to the grids to organize the building as a single block, then, thanks to demanding programs in terms of functionality, came the concern with spaces generated by the movement of people and things, corridors to traverse the building and corridors to distribute circulation within the sectors; concepts that were extended to the study of the form and design of the city. Examples of the possibility of using meshes by sectors of a building are shown, separated by corridors for people and cargo, according to the principle that the module for the organization of spaces may vary between sectors.

KEYWORDS: urban mesh; building design; urban design. 


\section{INTRODUÇÃO}

Apresenta-se, neste artigo, parte da experiência de um arquiteto diplomado em 1964, interessado em teoria, na prática de projetar edifícios, setores urbanos e na grata atividade de lecionar. Dos primeiros anos emerge o interesse por projetos em malha que aumentou na medida em que deixei de tomar por absolutos os preceitos da Arquitetura Moderna - a brasileira (segmento paulista) e seus contributos estrangeiros. Aprendi sobre urban design - 'projeto urbano' - pela experiência norte-americana e reforcei o hábito de, ao caminhar, observar os tipos de tecidos urbanos e o que faziam as pessoas pelo redor. Estive interessado em concursos públicos para anteprojetos, onde pelas proposições de arquitetura se esperava marcar a importância da entidade promotora e, modo geral, isto acontecia a partir de programas de necessidades bem simplificados. Observei o oposto com os projetos para clientes particulares onde pelo contato pessoal é habitual explicar de maneira direta as intenções, os desejos e o alcance financeiro do empreendimento pretendido. Daí, passei a considerar a importância de aprofundar o programa para quaisquer tipos de projeto. Perseguia-me de início a ideia de que a arquitetura moderna, como aprendi na Faculdade de Arquitetura e Urbanismo da Universidade de São Paulo, FAUUSP, continha o risco de levar ao sacrifício a qualidade dos espaços de maior permanência, na troca por um volume único, com estrutura em malha interrompida por um grande vazio, pátio interior e regulador das alas de espaços menores, localizados ao redor dele e modo geral com uma cobertura translúcida. Passei a duvidar da exaltação do valor atribuído a projetos elaborados por escritórios de destaque, brasileiros e internacionais. O que penso e hoje escrevo tem um conteúdo de crítica ao que produzi e a trabalhos de reconhecidos colegas, com o propósito de provocar a procura do caminho para acertar. Mostra variações possíveis do conceito e do emprego das retículas e o meu jeito atual de aplicá-las por setores de edifícios e da cidade. Procedimentos que conduziram meu interesse por projetos urbanísticos delimitados por setores, como os special districts à maneira do urban design norte-americano (BARNETT, 1974).

Utilizo exemplos tirados da minha prática profissional e nos escusamos pela falta de rigor acadêmico que isto possa ter, mas, entenda-se o procedimento como inerente a uma especulação intelectual. O texto é apresentado em tópicos, para ordenar os conceitos e apresentar considerações parciais, que se encerram em comentários finais.

O tópico 2, 'Plantas em malha e o projeto de edifícios', destaca o paralelo estabelecido entre exemplos nacionais e internacionais e a postura conceitual do autor representada por seus trabalhos como arquiteto. Mostra o entendimento de conceitos, sua aplicação em arquitetura, a absorção de ensinamentos interessantes e o cuidado para processá-los na concepção de projetos, por um jeito próprio de 'saber ver a arquitetura' (ZEVI, 2009).

O tópico 3, 'Retículas e o traçado da cidade', se refere ao movimento de pessoas ou coisas quando se direcionam ao edifício e no seu espaço interior. Usa-se a classificação de 'passagens que atravessam', 'que distribuem' ou 'locais'. Na cidade, 'vias que atravessam', 'que distribuem' e 'locais'. Modo geral, os fluxos que atravessam são os que definem os setores do edifício e da cidade. Acentuam-se as possibilidades para adotar um critério livre quanto à modulação das retículas por setor, para favorecer um dimensionamento conveniente de acordo com os programas para edificações e setores urbanos, de modo a dar liberdade à concepção de projetos e assim contribuir para estudos da forma urbana.

O tópico 4, 'Comentários finais', é onde se ressalta a continuidade de raciocínio que pode existir na passagem dos projetos de arquitetura para os estudos e traçados urbanos. A cidade entendida por partes, com atenção para os fluxos, para os setores, para os espaços de transição e para o desenho das quadras.

O tópico 5, 'Bibliografia', é restrita aos assuntos discutidos no texto que tenham relação direta com o dito por algum autor específico.

\section{PLANTAS EM MALHA E O PROJETO DE EDIFÍCIOS}

O traçado em retícula ou malha, quando pensado para resolver a planta de um edifício, objetiva racionalizar a construção e se associa à distribuição dos espaços, suas dimensões prováveis, os percursos das pessoas, da infraestrutura e o assentamento do prédio no terreno. É aplicável a qualquer dimensão de edifício e pode ser utilizado também para modular espaços exteriores e trechos de uma cidade. As retículas traduzem um modo de pensar que implica em simplificar as características únicas que poderiam apresentar determinados espaços, seja quanto a seu arranjo funcional, de significado ou ambiental (HABRAKEN, 2000).

Os edifícios em malha têm suas plantas regradas pela modulação dos elementos estruturais. Os componentes da edificação, industrializados e encontrados no mercado acompanham e sugerem o 
emprego de determinada modulação, cuja história está afeta à sabedoria do ser humano. É frequente se fazer a referência à modenatura utilizada em prédios da Arquitetura Moderna e vem à lembrança dos projetos de Mies van der Rohe, o Seagram Building em Nova lorque é muitas vezes destacado. A modulação por retículas traduz a opção que facilita o projeto de arquitetura, o traçado de um setor urbano e da infraestrutura. Conforme o programa de necessidades, caberá ao arquiteto fazer a alteração das dimensões do intercolúnio para admitir vãos diferentes e depois retornar ao padrão, ou, o arquiteto pode se valer das necessidades programáticas para interromper o padrão com uma estrutura diferenciada e chegar a uma volumetria final variada. Na Arquitetura Moderna, o grupo dos arquitetos racionalistas e o dos orgânicos são exemplos clássicos devido a sua base referencial de projeto: por um lado, arquitetos como Walter Gropius e Mies van der Rohe e, do outro, Frank Lloyd Wright e Alvar Aalto; entre os brasileiros, o contraste se encontra ao comparar as obras dos arquitetos Villanova Artigas e de Joaquim Guedes. Exemplos onde se expressam com clareza os limites do emprego do traçado em malha como suporte ao ideário de projeto. Em cada maneira de fazer, que tem a ver em parte com o emprego das retículas, importa a questão relativa à intenção formal representada pelo todo de uma edificação e isto é o que separa Mies de Aalto e Artigas de Guedes.

Pelo aspecto conceitual, estas diferenças influíram no meu trabalho profissional e se explicam pelo aqui exposto. Na Faculdade de Arquitetura e Urbanismo da Universidade de São Paulo, FAUUSP, onde me formei em 1964, foi marcante a presença e o conhecimento dos projetos do arquiteto-professor João Batista V. Artigas. Como aluno, eu pertencia a um grupo que aprendeu a projetar seguindo o exemplo do mestre. Um edifício caixa, de intercolúnio regrado, meios pisos ligados por rampas, espaço central coberto e translúcido, único, generoso e integrador dos visuais internas do prédio. Maneira de projetar que se estendia até uma edificação pequena, como uma casa. Aprendi a lição, e posso dizer que aprendi bem, pois, ainda recém-formado, participei por duas vezes de equipes classificadas em primeiro lugar em concursos de projetos patrocinados pelo Instituto de Arquitetos do Brasil, com trabalhos que atestam a influência de Artigas (Figura 1 e Figura 2).

Figura 1: Concurso, Mercado Público de Porto Alegre.

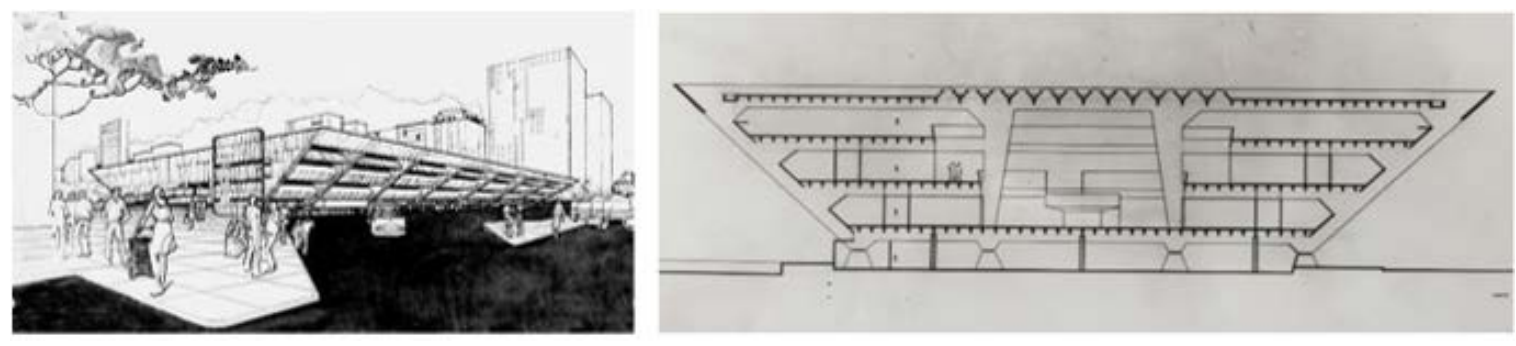

Fonte: Arquivo do autor.

Assinam este anteprojeto datado de 1967, o autor deste texto, José Magalhães Junior e Massimo Fiochi. Em seguida, com outro colega, o Eurico João Salviatti compusemos a dupla que venceu o concurso de anteprojetos para a Casa Edgard Santos, Centro Cultural da Universidade Federal da Bahia, que se realizou em 1970. Não tínhamos um escritório organizado e improvisávamos locais de trabalho; o suporte com as despesas vinha do que recebíamos por remuneração de free-lancer trabalhando para diversos escritórios.

Figura 2: Concurso: Casa Edgard Santos, Centro Cultural da Universidade Federal da Bahia.
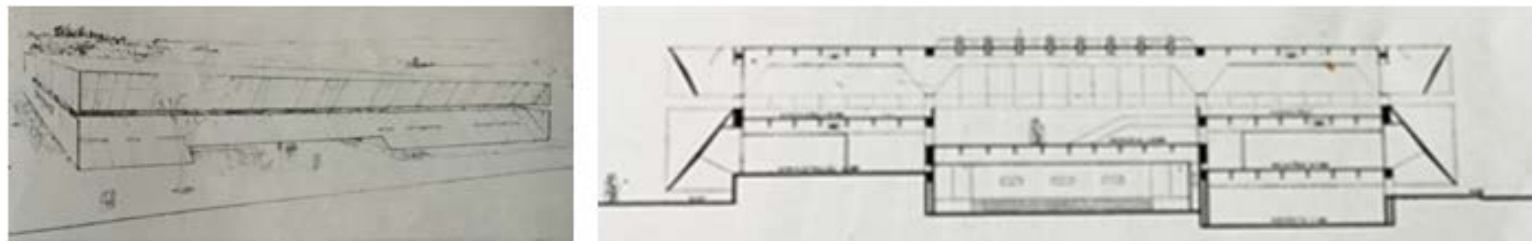

Fonte: Arquivo do autor.

Posteriormente, trabalhando para o arquiteto-professor Joaquim Guedes, aprendi o que ele costumava dizer sobre as características de um projeto. Algo assim: o que importa não é a complexidade volumétrica que um projeto possa ter, mas se aprofundar no entendimento do programa de necessidades, no estudo da insolação e ventilação, na racionalidade das junções das partes da construção, na redução de detalhes particularizados e na eficiência que eles possam fornecer. Estas palavras têm base de referência na obra do arquiteto Alvar Aalto, mas, foi muito importante ouvir isto do professor Guedes, quando eu estava ajudando 
a detalhar o projeto da Escola de Eletrônica de Campinas, por volta de 1969, já com as obras iniciadas. Conceito que afetou meu entendimento de como poderiam ser tratadas as partes de um edifício, no sentido de se encontrar as formas que melhor respondessem necessidades específicas e a articulação entre elas. Postura que não tira a possibilidade de desenhar cada parte através da modulação por malha. A Escola de Eletrônica, projeto de autoria do professor Guedes representou para mim este tipo de entendimento que, passado muito tempo, iria se manifestar em meus estudos sobre tecidos urbanos. Pela foto aérea apresentada na figura 3 , facilmente se percebe como as partes do edifício estão desenhadas por um critério de busca para a melhor construção e a forma de cada uma delas.

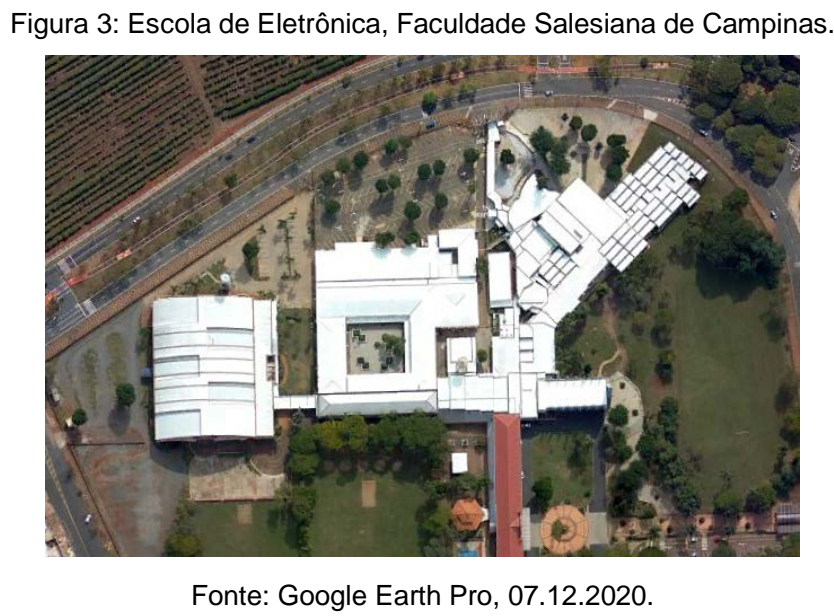

Sem haver suporte financeiro para continuar com os concursos de arquitetura nós - colegas da época estudávamos, desde os mais antigos, e destaco entre os projetos em malha o anteprojeto da Universidade Livre de Berlim (1962), cujo primeiro prêmio foi para a equipe francesa de Alexis Josic, Georgis Candilis, Shadrach Woods e do colaborador alemão Manfred Schiedhelm. O início da construção data de 1967 e ocupou uma parcela de formato aproximadamente retangular, 10ha do total de $35 \mathrm{ha}$, pertencente à universidade. A proposta mostrou como ocupar o espaço e permitir ampliações futuras, resolvendo o programa através de pavilhões de dois e três pavimentos ordenados segundo uma retícula de passeios cobertos, que ladeavam pátios internos de acesso aos locais de trabalho, reuniões informais e auditórios; desenhados à maneira das cidades árabes (segundo o memorial dos autores do projeto). Estrategicamente situadas na malha, as áreas descobertas formariam um estoque para as ampliações futuras e a consolidação de pátios ajardinados. Passados cinquenta anos se pode observar através de fotos aéreas (Google Earth Pro) como evoluiu a ocupação dos espaços (Figura 4).

Em 4A, aparece o plano do campus datado de 1967, conforme o desenho do concurso; em 4B, o campus em 2010, com o projeto construído; em 4C, imagem de 2020, aparece dentre outras pequenas ampliações, uma grande forma esférica; em 4D, destacamos o Rost and Silberlaub que é a inserção esférica introduzida na malha original do campus, projetada por Foster + Partners em 2005. Norman Foster propôs um volume que se ajustou no espaço disponível reservado para expansão da malha proposta pelos vencedores do concurso e pôs à luz a indagação sobre como poderia vir a ser a ampliação futura em um conjunto construído pensado para hoje. Este 'hoje' pode estar muito lá atrás, como no caso da ampliação do Museu do Louvre, através da pirâmide projetada pelo escritório Pei, Architects Associates. Atesta-se, assim, a imprevisibilidade da ampliação que pode sofrer um conjunto edificado. Nossa reflexão se faz sobre a dificuldade para controlar as expansões futuras de um projeto, pois, surgem programas imprevisíveis, a participação de outros arquitetos é inevitável, o que pode enriquecer de modo inovador a qualidade de algo já reconhecido por ser bom. 
Figura 4: Evolução da ocupação do campus da Universidade livre de Berlim.

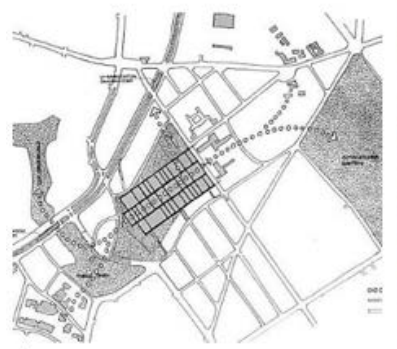

A

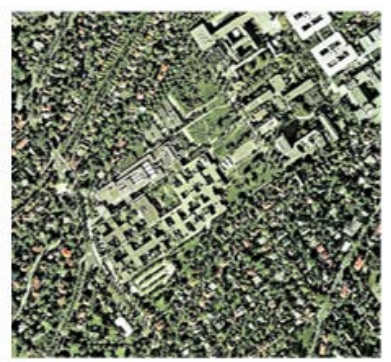

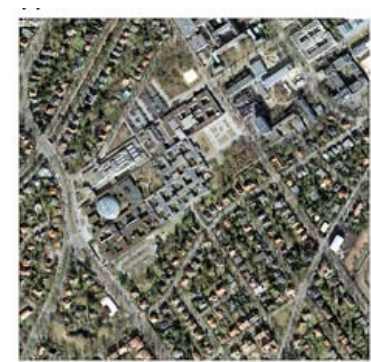

C

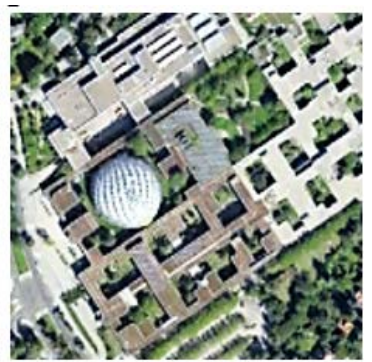

Fontes: Wikimedia e Google Earth.

O projeto para Berlim e outros projetos de responsabilidade do escritório Candilis, Josic e Woods aplicando o conceito de malha repercutiram internacionalmente e interessa sua influência no Brasil. Em São Paulo, tivemos o concurso de anteprojetos para um edifício da a Secretaria da Agricultura, 1968, em que saiu vencedora a equipe formada pelos arquitetos P. J. V. Bruna, Arnaldo Martino, Sérgio Bergamim e J. G. S. de Castro, inspirado no conceito de malha (Figura 5).

Figura 5: Secretaria da Agricultura e Abastecimento, Parque do Estado São Paulo.

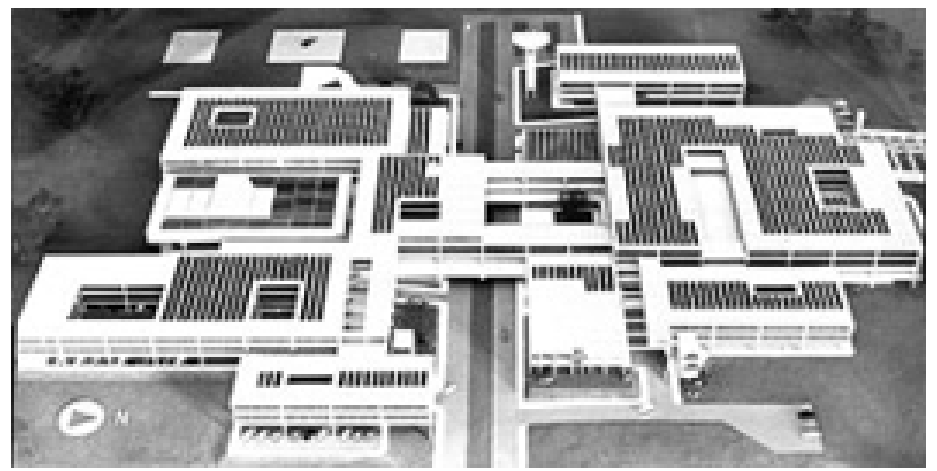

Fonte: Maquete do anteprojeto, Revista Acrópole, n. 357, dezembro de 1968

Outra forte influência do projeto da Universidade Livre de Berlim foi nos campi de algumas universidades brasileiras, como os projetos em malha para prédios de grande área construída, da Universidade de São Paulo e da Universidade Federal de Minas Gerais, campus de Belo Horizonte. Neste, foram construídos trechos com inspiração em Berlim que não se expandiram por inteiro, mas por trechos isolados, como mostra a foto aérea. Em Belo Horizonte, pela largueza do campus e por preferência em relação à orientação solar, se observam mudanças da direção dos prédios mais recentes que optaram pela direção Norte-Sul (Figura 6).

Figura 6: Trecho do campus da Universidade Federal de Minas Gerais, Belo Horizonte, MG.

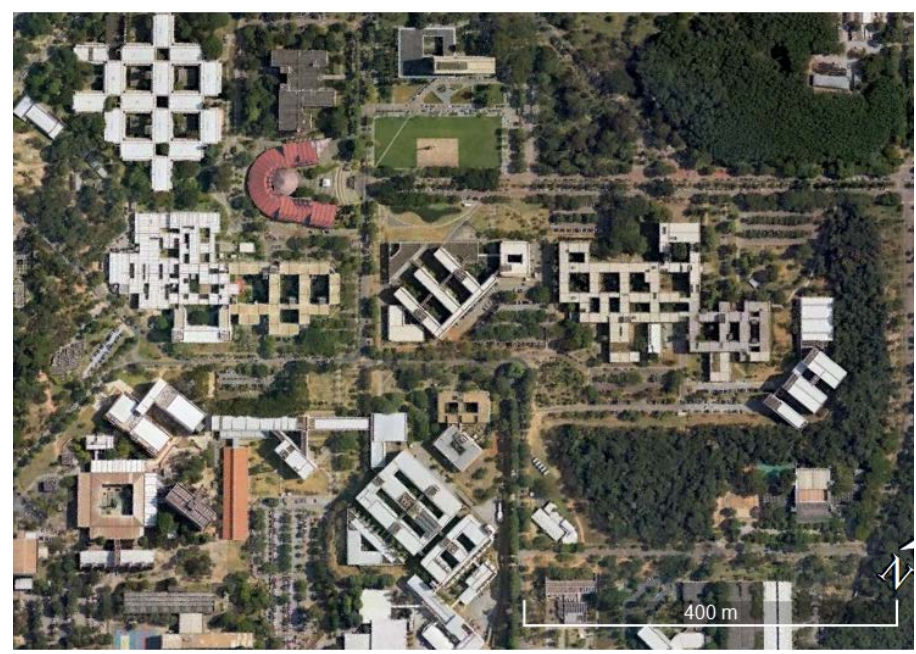

Fonte: Google Earth Pro, 2020. 
Acompanhando o descrito acima sobre o vir a ser de um projeto, prosseguimos no aprendizado. Primeiro, o conhecimento da investigação do arquiteto-professor Kevin Lynch sobre a percepção da imagem da cidade, que através de critérios como legibilidade (legibility), construção da imagem (building the image), estrutura e identidade (structure and identity) e imageabilidade (imageability), definiu cinco elementos de análise visual da forma da cidade: caminhos ou vias (paths), limites (edges), vizinhanças (districts), nós (nodes) e marcos (landmarks). Isto trouxe para nós que ensaiávamos uma maneira particular de projetar edifícios e entender a cidade uma sistemática firme sobre a forma dos espaços, através do livro The image of city publicado em mil novecentos e sessenta e dois (LYNCH, 2006).

No intervalo de tempo entre 1964 e 1971, experimentei caminhos distintos. O oferecido pelo professor Guedes, a experiencia de autoria do projeto para uma escola pública e o trabalho no escritório do professor Gasperini, (Croce, Aflalo e Gasperini Arquitetos Associados), onde a elaboração de projetos apoiados em retículas era a tônica principal. Em meio a estas atividades conhecemos outro livro publicado por Kevin Lynch, título Site Planning e este nos ajudou a apaziguar as incertezas de jovem arquiteto. Nele o professor explicou algo que veio ao encontro de nossas ideias.

O sítio existente e os propósitos pelos quais ele será modificado são as duas fontes de onde nasce o projeto. Estas duas fontes estão curiosamente relacionadas. O propósito não pode ser confirmado até que sejam conhecidas as limitações que o sítio impõe, e o sítio não pode ser analisado até ser expresso o propósito para o qual ele será utilizado (LYNCH, 1962, p. 9)

O projeto para a escola pública, EE Brigadeiro Gavião Peixoto, foi elaborado em parceria com o arquiteto Danilo Bassani. O sítio destinado ao projeto se situava em um platô elevado em relação à rua (era uma quadra de futebol de várzea) e o prédio deveria atender a crianças de três faixas etárias (na época, ensino pré-primário, primário e médio). Para atender a esta condição localizamos as crianças menores e as dependências administrativas em um nível intermediário e de fácil acesso pela calçada da rua; um espaço intermediário para amenizar a subida até o platô principal. Os critérios usados para organizar os espaços desta escola, situada no distrito de Perus, São Paulo, SP, foram expressos por um memorial explicativo do projeto. Dele destacamos o diagrama dos movimentos em relação aos locais de maior permanência, quesito que interessa a como mapear o programa de necessidades e usar as retículas para cada setor do projeto.

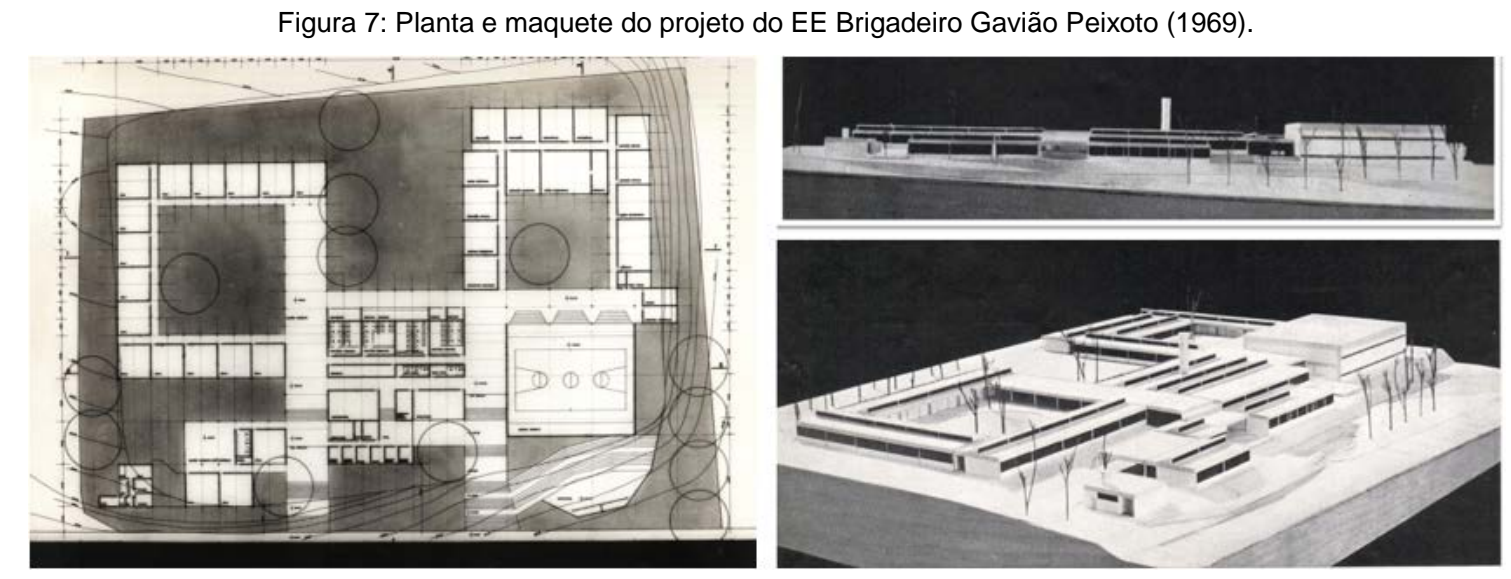

Fonte: Arquivo do autor.

O projeto, datado de 1969 e a escola inaugurada em 1973, foi uma experiência para projetar utilizando setores separados por circulações que atravessam e distribuem os fluxos das pessoas e cargas. Conceito que adoto atualmente para os estudos de tecidos urbanos e, pensando nas soluções em malha, elas podem ter a modulação mais bem adequada a cada setor do edifício. Doutra parte, a preocupação em associar a construção dos espaços internos aos externos levou a parcerias com colegas ligados às disciplinas de paisagismo e conforto ambiental, tanto quanto possível, pois isto depende da disponibilidade do cliente para arcar com despesas adicionais ao projeto de arquitetura. Neste sentido, considero a obra do arquiteto Richard Neutra como uma referência muito importante (NEUTRA, 1969).

Em Perus, o procedimento de trabalhar a arquitetura junto com o conforto ambiental do edifício e o paisagismo foi viável por ter sido este projeto experimental, para testar um novo programa de necessidades desenvolvido pelo departamento de planejamento do Fundo Estadual de Construções Escolares, coordenado pela arquiteta Mayumi W. de Souza Lima, uma especialista em escolas públicas. Houve a colaboração dos arquitetos Roberto C. Cardoso e Antônio A. Antunes para o paisagismo e do arquiteto Luís Carlos Chicherchio para o conforto ambiental. 
O terreno da escola com cerca de um hectare e meio tem acesso através da via que atravessa o limite externo do bairro Vila Perus, a rua Mogeiro, e foi destacado de uma área de reserva verde pública acessível pela mesma via pública. A gleba assente em uma plataforma de nível elevado com relação a rua Mogeiro abrigava um campo de futebol de várzea. Pelo projeto, o acesso ao platô intermediário e ao nível do campo de futebol, elevado a três metros e meio da rua, se faz por uma rampa de pequena inclinação e por escadas. O espaço intermediário com a finalidade de acolhimento, distribui a circulação para o nível mais alto através de dois eixos perpendicures à rua e responsáveis pelos caminhos que atravessam o prédio e para as circulações internas. O setor destinado às crianças menores, três salas de aula, o recreio coberto e seus apoios se situam no platô intermediáio, em um canto do terreno ambientado para elas. As plantas configuradas por retículas são as que se julgou apropriadas para cada um dos conjuntos de espaços.

Pela foto do Google Earth Pro apresentada na figura 8, é possível visualizar as partes onde a malha se modifica e também a posição dos pátios descobertos com relação às circulações que atravessam a edificação. É interessante notar a quadra descoberta para as crianças (seis a dez anos), não prevista no programa inicial, que foi implantada por volta de 1990 junto à circulação coberta e à divisa de fundo do terreno. Em 2010, ela foi coberta sem fechamentos laterais e assim ficou como um novo espaço integrado ao sistema de circulação e recreio existente. O relato deste fato mostra como um adendo anexado trinta anos depois se integrou ao prédio em malha. Na mesma figura, uma foto antiga (1974), mostra o patamar intermediário de distribuição das circulações, onde um grupo de pessoas se encaminha para uma delas. Os termos 'circulação que atravessa' e 'circulação que distribui' os estamos empregando para que se atente a semelhança com a 'via que atravessa' e a 'via que distribui', adotados posteriormente para o estudo da cidade.

Figura 8: EE Brigadeiro Gavião Peixoto, contexto urbano.

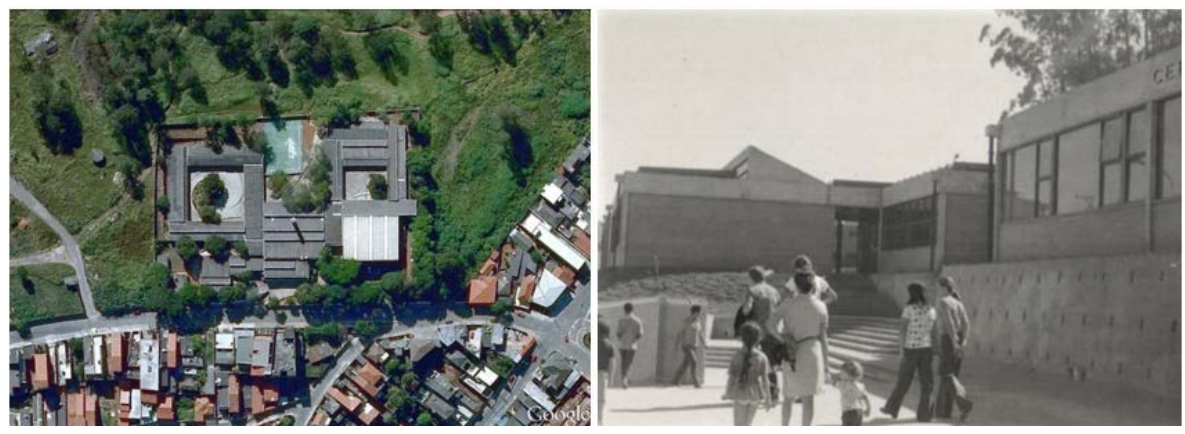

Fonte: Google Earth Pro, 2016 e foto de 1974, do autor.

Ao final de 1971, deixei o escritório do professor Gasperini (São Paulo) e com a esposa e um filho fomos viver em Brasília. Primeiro, foi a novidade de mudar para a cidade-capital do país e assumir atividades de professor na Universidade de Brasília, UnB, com a perspectiva de trabalhar no CEPLAN, Centro de Planejamento, onde, em paralelo aos compromissos acadêmicos, participei de três projetos significativos para a temática central deste artigo. Foram destinados para atividades de ensino e pesquisa nas áreas de ciências da saúde e tecnologia. Depois de dois anos, a primeira etapa do Centro de Medicina Tropical estava terminada, tendo sido financiada por entidades internacionais de fomento à pesquisa; foi a primeira etapa de um projeto concebido para ser ampliado por partes.

Em agosto de 1975, saí para atender a bolsa no exterior, com a esposa, o filho paulistano e uma filha brasiliense. Rumo aos Estados Unidos da América, com apoio da UnB e da Coordenação de Aperfeiçoamento de Pessoal de Nível Superior (CAPES), indo para a Graduate School of Design, cursar o Urban Design Program, Universidade de Harvard. É permitido aos alunos de Harvard cursar disciplinas no MIT (Massachussets Institute of Technology) e vice-versa, e assim tive a oportunidade de cursar uma disciplina ministrada pelo professor Kevin Lynch e outra por Nicholaas John Habraken, arquiteto holandês conhecido por sua contribuição em trabalhos de racionalização de projetos para a habitação social e de seus conceitos no campo da participação do usuário no processo de projetar habitação em grande escala. Ele desenvolveu a teoria de suportes e unidades destacáveis, apresentado no livro Supports, 1972, e publicou depois The Structure of the Ordinary, 2000 onde conceitua questões de controle e da forma do ambiente natural e construído (HABRAKEN, 1972; 2000).

As disciplinas de Harvard abrangendo conceitos e métodos de projeto urbano somadas às atividades de estúdio, visitas a locais históricos e áreas de revitalização, em Cambridge, Boston e outras cidades próximas, ajudaram a consolidar meu respeito pela teoria e aguçar minha vontade de descobrir princípios 
de projeto pelo conhecimento dos lugares, incluindo as pessoas. Aproveitei das oficinas (charrets) formada por administradores, técnicos voltados para a implementação de projetos e a comunidade, onde se inclui a forte participação dos pequenos e grandes empreendedores privados. Assumi ser um procedimento indispensável para a arquitetura e o projeto urbano identificar com clareza as partes que influem no programa de necessidades e a partir daí estabelecer os setores de permanência e a natureza dos fluxos de movimentos.

De volta a Brasília, ao final de 1977, acompanhei a implantação das instalações para o conjunto das Ciências da Saúde e trabalhei no plano de desenvolvimento físico do campus da universidade, hoje denominado Campus Darcy Ribeiro. Minha tendência para observar o contexto de um projeto, veio mais organizada na volta dos EUA. Ou seja, conhecer o local andando a pé descontraído e desapegado da carga de dados interdisciplinares pré-existentes; explorar possibilidades sejam para o projeto do edifício ou da cidade, fora da linearidade dos códigos oficiais ou das soluções fáceis de escritório. Hoje, escrever sobre projetos dos quais fui responsável tem o objetivo de explicar os princípios experimentados para os edifícios e mostrar a continuidade para a análise e proposições relativas à cidade. Uma continuidade percebida após tanto tempo ter passado!

Na figura 9, aparece o Núcleo de Medicina Tropical. Em 9A, a construção inicial, datada de 1974, possuía apenas um pátio (esquerda na foto). Em 9B aparece a configuração em 2021. O prédio cresceu em três etapas por incrementos pequenos, que traduz o dito piecemeal development, comentado por Christopher Alexander, em interessante análise que faz sobre o campus da Universidade de Oregon (ALEXANDER, 1975).

Figura 9: Núcleo de Medicina Tropical.
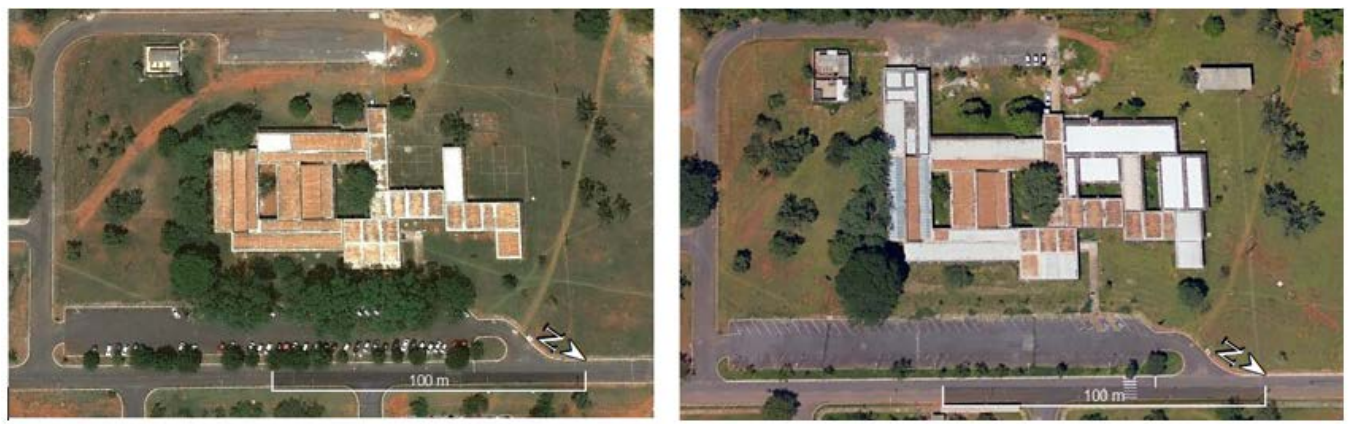

Fonte: Google Earth, 2010 e 2019.

Para o projeto do Núcleo de Medicina Tropical se aplicou um sistema de retículas como o utilizado no projeto para a escola de Perus, SP. No projeto das faculdades para saúde e tecnologia, de dimensões maiores e programas complexos, mantido o critério de estudar o espaço por partes, se chegou ao conceito de que as circulações que atravessam seriam integradas por um pátio interno principal além de outros, menores, que proporcionassem boas condições de aeração e ventilação para as salas de trabalho. O pátio maior seria tratado como uma praça interna ao prédio.

No campus ainda não existe um sistema de calçadas para pedestres acompanhando o alinhamento da guia da faixa de rolamento e a tradição é os prédios serem implantados com grandes recuos de frente e laterais. No caso da implantação da Faculdade de Ciências da Saúde, os recuos laterais foram previstos como áreas possíveis para expansão da faculdade, por justaposição ao existente ou blocos separados interligados por passarela coberta até um dos corredores que atravessam a escola (Figura 10). 
Figura 10: Faculdade de Ciências da Saúde, 2020.

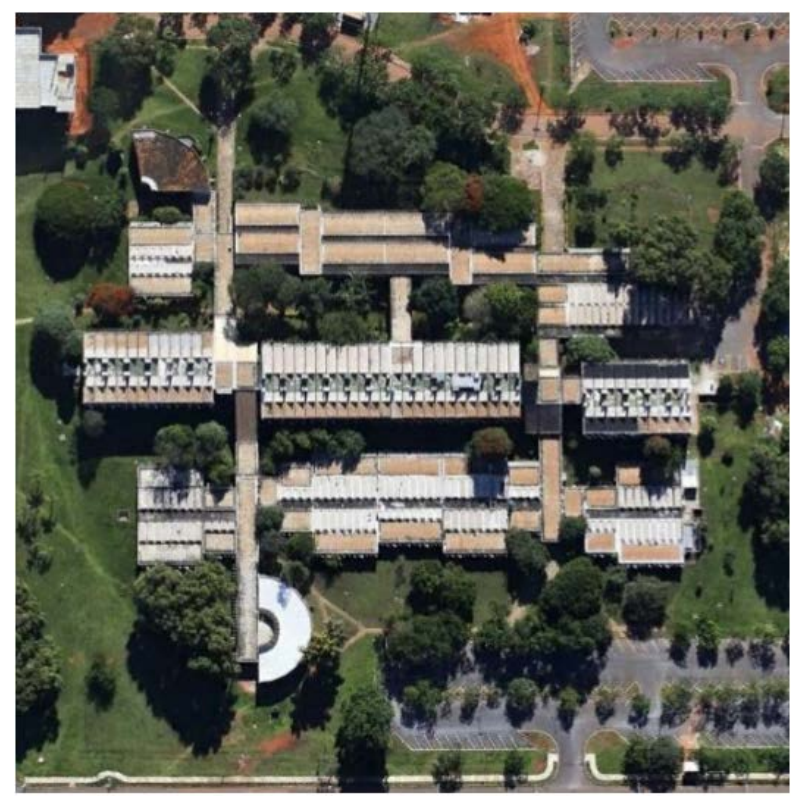

Fonte: Google Earth Pro, 2020.

$\mathrm{Na}$ figura 11, aparece o espaço externo marcado pelo auditório que acusa a presença de uma 'porta principal' o acesso à diretoria e às secretarias da faculdade. Do espaço de acesso, grande porque serve ao gabinete do diretor e ao foyer do auditório, segue um corredor que atravessa e vai até ao outro extremo do conjunto construído, onde o tipo de acesso é mostrado pela segunda foto desta figura. Como ele é próximo à parada de ônibus, é muito utilizado pelos estudantes e a área externa próxima à porta serve como um espaço de transição, de encontro de estudantes, antes e depois das aulas.

Figura 11: Faculdade de Tecnologia, acesso ao prédio levando a circulação interna que o atravessa.
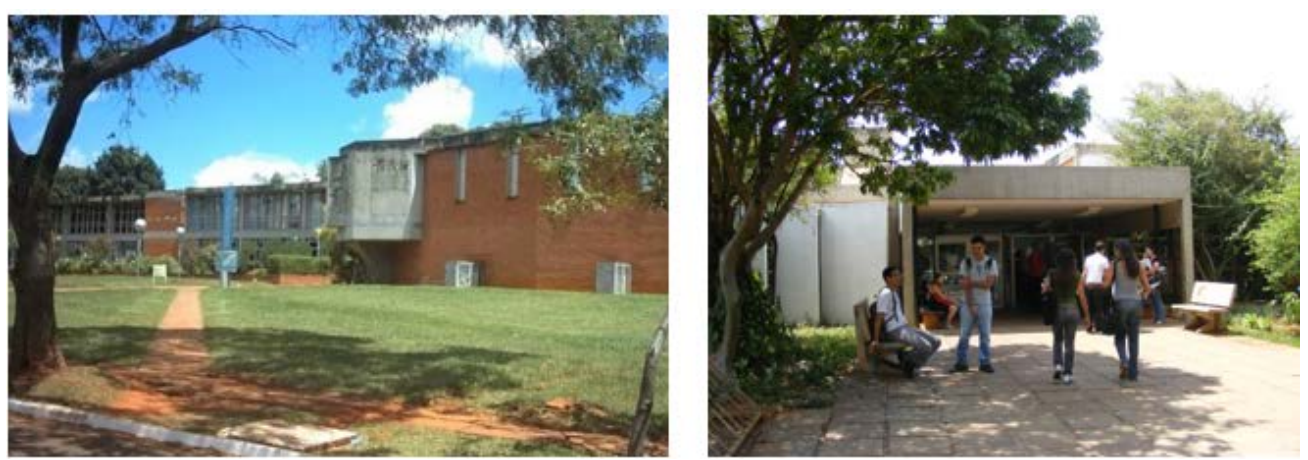

Fonte: Fotos do autor

A figura 12 serve como ilustração dos comentários sobre as passagens e corredores. Na foto da esquerda, aparece um corredor que atravessa tendo largura de seis metros, que permite o acesso às circulações de distribuição e aos pátios. Junto aos cruzamentos, ou nós, são colocados banheiros, salas de interesse comum, escadas e outros elementos de apoio. No espaço que separa as diferentes partes construídas e como parte do sistema de circulação estão localizados os dispositivos para vencer os desníveis de meiopiso resolvidos por rampas e escadas. Existe neste prédio um elevador grande tipo monta-carga que atende ao bloco de laboratórios de pesquisa e a pessoas com necessidades especiais (bloco central do conjunto, figura 10). Na foto à direita da figura 12, aparece um acesso secundário externo, local pensado para receber uma cobertura tipo passarela de dois metros de largura, como eventual ligação a uma futura construção. 
Figura 12: Circulação interna que atravessa.
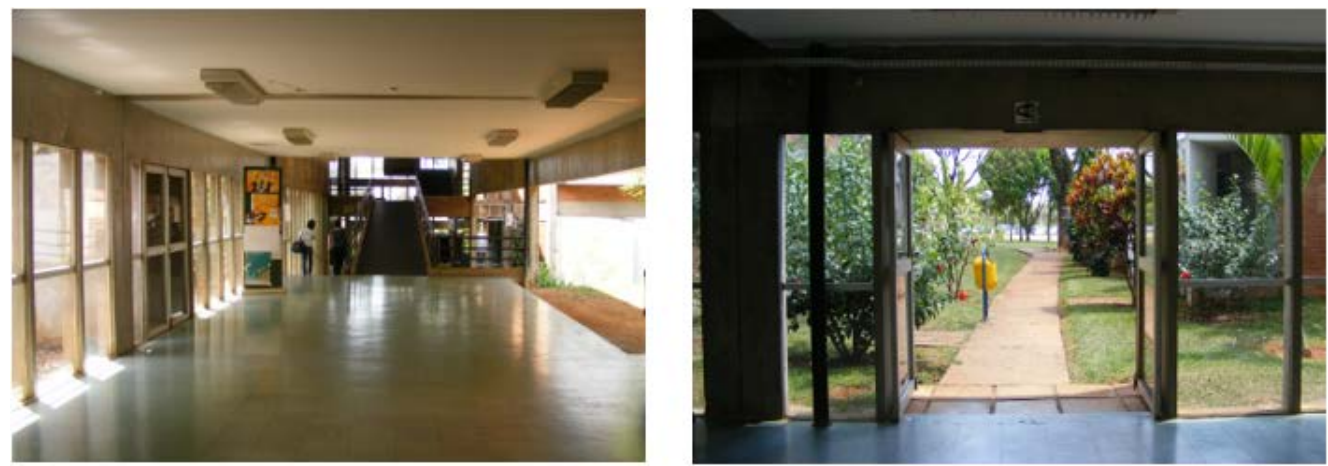

Fonte: Fotos do autor, 1994.

O pátio maior é desenhado como uma praça e serve para a circulação e outras atividades de convivência (Figura 13). Existe uma circulação do tipo 'loggia', correspondente aos dois pavimentos das salas administrativas. As pessoas normalmente circulam aproveitando o sombreado da loggia ou das árvores e, nos dias chuvosos, circulam mais pela loggia, cuja largura é de três metros. Na primeira foto, aparece o pátio vazio em um dia de feriado e realça o tipo de espaço enclausurado, um simples pátio. Na foto à direita, com vista no sentido oposto, o pátio está movimentado servindo como ponto de encontro das pessoas e passagem, devido aos atrativos existentes.

Figura 13: O pátio interno principal.
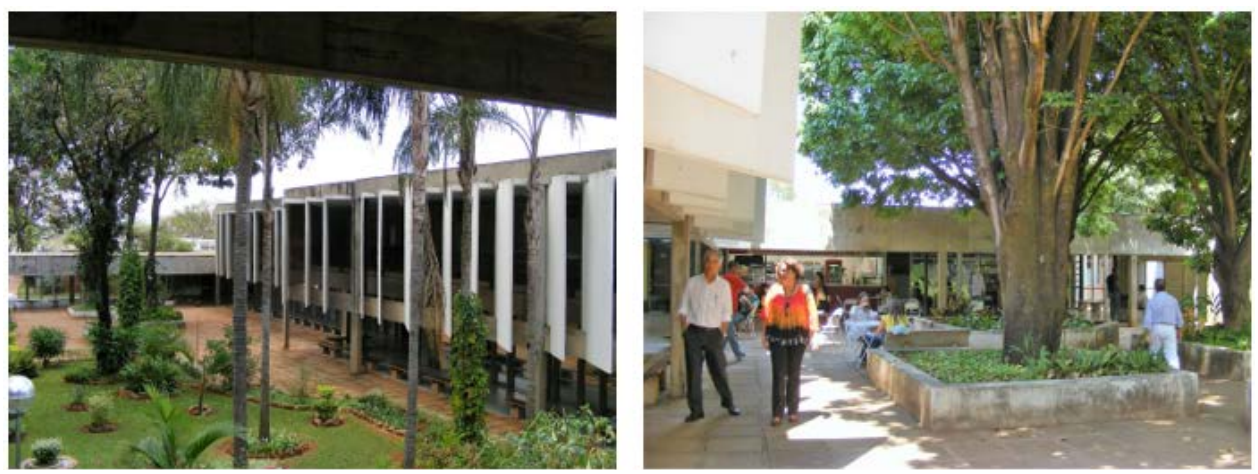

Fonte: Fotos do autor.

O prédio da Faculdade de Tecnologia faz parte do setor do campus destinado às engenharias e seu projeto foi elaborado em conjunto com o prédio das Ciências da Saúde. Situa-se junto à L3 Norte, uma via que acompanha toda a Asa Norte de Brasília. Daí a facilidade dos acessos para as pessoas e cargas, como se pode aferir pela figura 14. O acesso dos visitantes ao prédio se faz por uma via transversal ao campus, de ligação entre a L3 Norte e a via interna a ela paralela, que distribui os fluxos para as vias locais. Pode ser observado na foto aérea uma travessia de pedestres que vai desde um ponto de ônibus localizado na via L3 até o Instituto Central de Ciências (o 'Minhocão'), passando através do prédio da Tecnologia, fora um trajeto externo que passa pelos laboratórios grandes (à esquerda na figura).

Figura 14: Faculdade de Tecnologia.

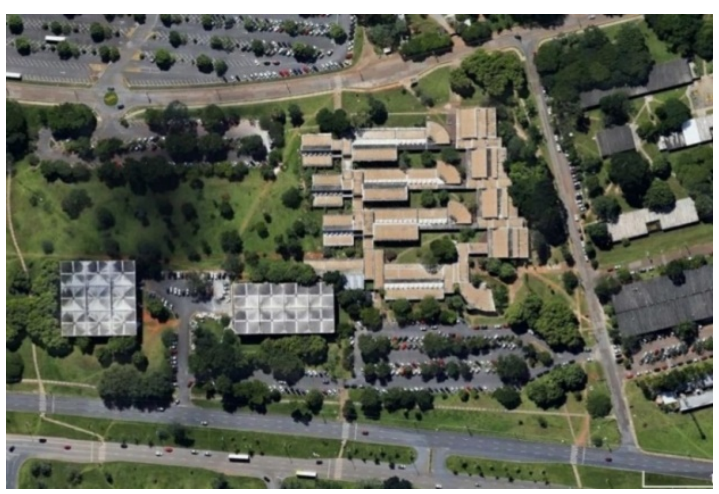

Fonte: Google Earth Pro, 2021. 
O 'Minhocão' como catalizador da circulação de pedestres desde a L3 Norte deixa o prédio da Tecnologia como espaço urbano intermediário como se pode observar pela foto aérea, aspecto que influiu na implantação do prédio. A implantação define uma esquina deixando uma boa área para expansão futura que se prolonga após os blocos grandes para laboratórios (Figura 14).

Seguindo os mesmos conceitos utilizados para o projeto do edifício da área de saúde, as circulações internas seguem o critério de travessia e distribuição, com atenção aos acessos e à inserção de pátios internos. Em Brasília, na época deste projeto (1970) e do projeto da Saúde, as questões de segurança não eram tão importantes como agora; hoje em dia, os acessos precisam ser controlados: uma lição para os novos projetos (Figura 15).

Figura 15: Faculdade de Tecnologia, acesso pela área central do campus.
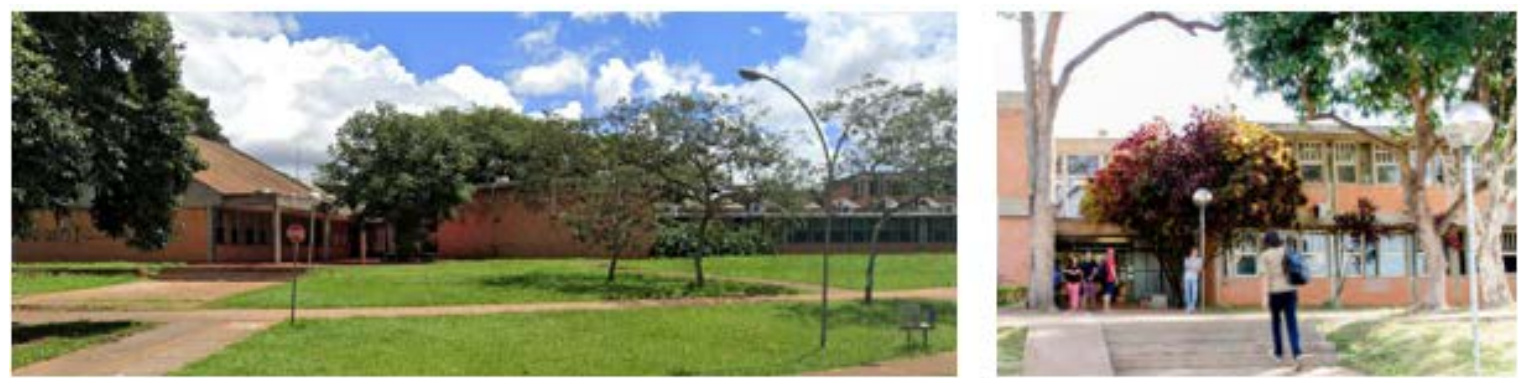

Fonte: Wikimedia Commons, 18.02.2021.

Na figura 15 à esquerda, aparece a vista desde um nó de circulação, mostrando o pátio ajardinado e um percurso que atravessa acompanhando salas administrativas. À direita, um lugar intermediário do pátio principal onde o trecho alargado da cobertura, destinado para convivência informal, vem sendo usado para pontos de encontro e trabalho, uma situação possível em Brasília devido ao seu clima ameno. O Guia Arquitetura Brasília, usando um texto de Sylvia Ficher e Geraldo S. N. Batista, publica 'a Faculdade de Tecnologia oferece um dos ambientes mais agradáveis do campus, graças à integração de seus espaços internos e externos' (FICHER; BATISTA, 2000).

Figura 15: Faculdade de Tecnologia circulação e pátio.
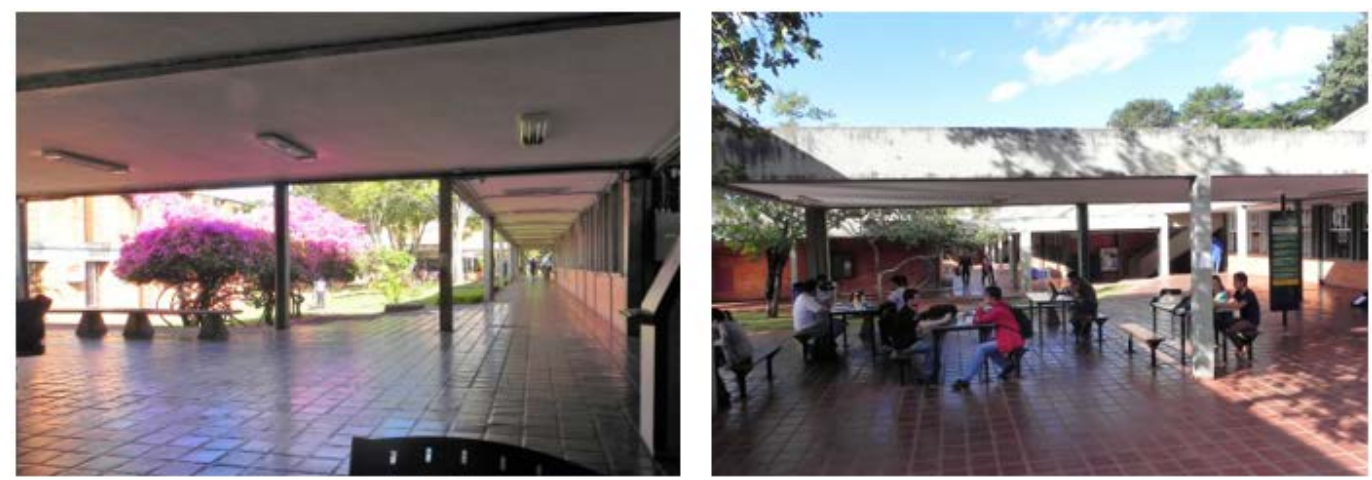

Fonte: Fotos do autor, 2018.

Os projetos de arquitetura dos edifícios da Faculdade de Ciências da Saúde e de Tecnologia elaborados com a equipe técnica do CEPLAN são de responsabilidade do autor e do arquiteto-professor Érico P. S. Weidle. Os projetos de paisagismo são de responsabilidade do arquiteto-professor Eurico J. Salviatti. Houve assessoria técnica para as questões de conforto ambiental pelo arquiteto-professor Marcio $\mathrm{V}$. Boas. Colaboraram com a equipe, arquitetos ex-alunos e alunos estagiários da UnB.

O projeto apresentado a seguir (Figura 16) resultou de um convenio de assessoria técnica entre a Universidade Federal de Sergipe, UFS, e a UnB; a obra foi financiada pelo BID e da mesma forma que os dois projetos anteriores foi desenvolvido no CEPLAN no ano de 1981. Usando uma visão retrospectiva afirmo que este projeto possibilitou-me dar um passo adiante no sentido de quem busca a compreensão dos tipos de edificações e dos tipos destinados ao movimento de pessoas e cargas na cidade, a partir da arquitetura. Foi uma evolução no sentido de levar a ideia dos eixos que atravessam, distribuem e definem setores de espaço para o estudo da forma da cidade e seu projeto. O projeto de Aracajú foi um simples ensaio, para o conceito depois alargado para incluir o estudo de elementos urbanos e o procedimento de corredores e subáreas (MACEDO, 2021). 
No campus da UFS em Aracajú, uma via para pedestres foi definida para separar dois setores do campus: saúde e tecnologia. São glebas vizinhas e uma via para pedestres foi traçada seguindo a linha de divisa que os separa. Para criar um ponto de interesse no caminho que tem cerca de duzentos e cinquenta metros foi desenhada uma pequena praça. Pretensiosamente seria um boulevard, onde as janelas, os pontos de acesso, a vegetação, o mobiliário e a sinalização compõem o espaço público. Por trás do renque longitudinal das salas voltadas para ele, existem circulações cobertas que o acompanham e cruzam os nós de acesso aos blocos transversais. O projeto de 1981 enseja o tecido de uma cidade grande, a metáfora do boulevard poderia ser considerada simulacro de uma via para pedestres da cidade.

Figura 16: Centro de Ciências Biológicas e da Saúde, UFS, Universidade Federal de Sergipe.

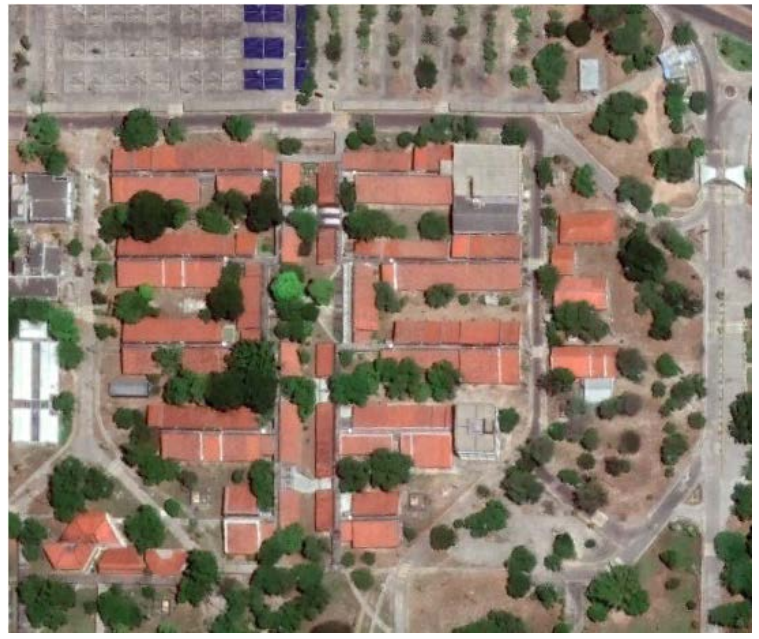

Fonte: Google Earth Pro, 2021.

Os renques laterais formados pelas salas de administração e que servem de apoio às atividades de ensino e pesquisa, ainda pensando na cidade tradicional, equivaleriam aos imóveis voltados para um eixo principal de circulação, um 'corredor que atravessa'.

O sistema construtivo foi definido para ser econômico e pelo uso de materiais locais. Assim se utilizou a modulação de 3,00m para o intercolúnio dos prédios, acompanhando a largura recomendada para os laboratórios, possível também para as salas de aula expositivas. Os vãos laterais são no máximo de 9,00m, com vigas cada 3,00m para receber lajes pré-moldadas leves de concreto e cerâmica; a cobertura é feita em telhas de cerâmica. Na figura 19, aparecem fotos da construção e da maquete de estudo do sistema construtivo.

Figura 17: Trecho do conjunto, em obras.
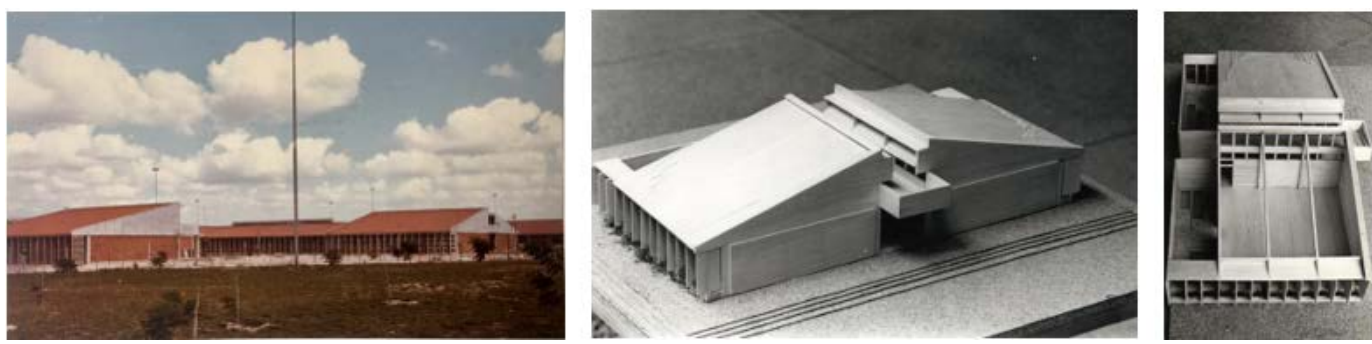

Fonte: Arquivo do autor.

\section{RETÍCULAS E O TRAÇADO DA CIDADE}

Com respeito ao projeto para os setores de uma cidade, uma referência marcante quanto à modulação por retículas é o trabalho do arquiteto grego Hipodamo, que concebeu o plano para Mileto (sua cidade natal) aplicando uma solução em malha com três tamanhos para a modulação das quadras, por setores, ajustando as retículas para que melhor respondessem à demanda de diferentes castas sociais. Ele aproveitou as áreas de relevo plano para as partes de natureza repetitiva e desenhou quadras de formato quadrado, com tamanhos diferentes para atender ao programa da subdivisão em lotes conforme as castas da sociedade de Mileto; os enclaves com terrenos acidentados foram reservados para os prédios de interesse comum, únicos e resultantes de programas específicos; isto, em 450 AC aproximadamente (MOHOLY-NAGY, 1968). 
A malha retangular tem servido de suporte para projetos desde a antiguidade, na Asia, Europa e Américas, e a sua história é importante para entender desde os traçados tradicionais até as concepções de hoje. Tenho observado o tecido de cidades tradicionais de uma maneira sistemática desde os anos 1990, com o olhar da arquitetura e da experiência continuada de lecionar disciplinas de Urbanismo. Foi o despertar para a escala urbana, o andar por trechos da cidade, procurar uma maneira de compreender sua forma e propor projetos na escala urbana. Percebi a importância do movimento das pessoas e de cargas que atravessam e distribuem seus trajetos pela cidade. Classifiquei o suporte para estes movimentos em 'vias que atravessam' e 'vias que distribuem' a circulação para as 'vias locais”. Elas ocupam uma porção significativa do espaço da cidade e contribuem para a definição do uso e ocupação do solo das faixas lindeiras de lotes das quadras ao longo de seu percurso. As vias locais têm o caráter próprio dos espaços de vizinhança. Subdividindo desta maneira, fazemos o parcelamento da cidade por 'setores' e 'subsetores' através das vias que atravessam e distribuem. Destaca-se a importância dos lotes das faixas lindeiras destas vias; elas dão origem ao 'corredor' formado pela faixa originada pela linha irregular dos fundos de lotes existentes em ambos os lados de uma via. Nas cidades, em especial nas tradicionais, estes corredores se cruzam e estabelecem uma porção central ou miolo chamado de 'subárea' (Figura 18).

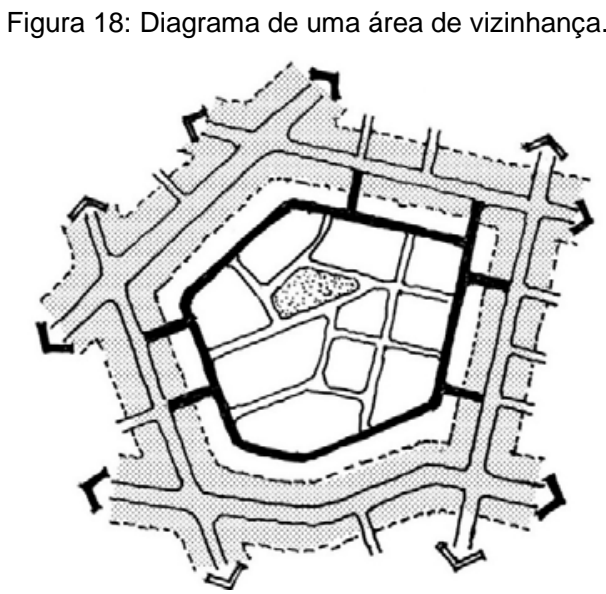

Fonte: Diagrama do autor, 2018.

O diagrama representa os elementos identificados para um setor urbano. O 'setor' é delimitado pelas frentes dos lotes das quadras voltadas para as vias que atravessam ou distribuem. O corredor corresponde à faixa estabelecida pelos fundos de lotes (em tracejado no diagrama) voltados para as vias que atravessam ou distribuem definidoras dos corredores (pontilhado). No diagrama se realçou um conjunto de vias internas que em alguns lugares da cidade se encontram quase nesta situação ou que poderiam ser induzidas para isto por políticas públicas para implantação de projetos urbanos na escala do setor ou subsetor. Esta configuração de espaços poderia ser chamada de 'área de vizinhança protegida', por haver barreiras que impedem o tráfego de passagem. A área interna à linha pontilhada dos fundos de lotes do corredor é a que define uma 'subárea'. Estes conceitos são úteis para projetar partes da cidade.

\section{COMENTÁRIOS FINAIS}

Interessar-me pelos traçados em retícula onde intuitivamente associei a prática e a teoria, considero um fato relevante pois serviu para delinear o perfil profissional que tenho agora. $O$ começo foi pelo Movimento Moderno e o ideário do Team X, depois conheci Brasília e algumas cidades do exterior e me fixei em São Paulo. O meu interesse sobre os traçados em retícula evoluiu desde que fui levado a organizar programas de necessidades muito detalhados e projetar quase em conjunto; estudar as partes do edifício ou setores e verificar como eles poderiam se interligar; estudar quais seriam os tipos de espaços melhores para os percursos e a convivência das pessoas: corredores, saguões, pátios abertos. Entendendo o edifício desta forma não há porque se prender a um sistema modular único de retículas, como fazia Mies van der Rohe: o módulo adotado para cada setor pode variar, também, para o traçado das áreas comuns, tanto nos edifícios como no projeto para setores urbanos. Em São Paulo, desenvolvi estudos que levaram aos procedimentos de estudar e projetar a cidade através dos corredores e subáreas (Figura 19). 

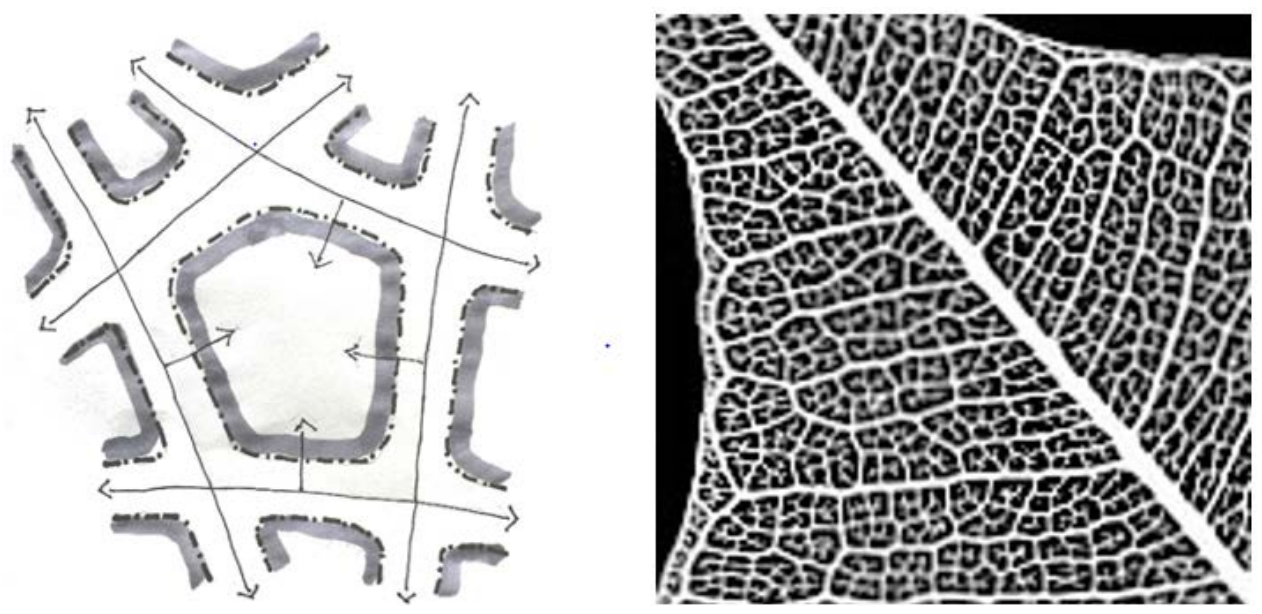

Fonte: Diagrama do autor (à esquerda) e micrografia de uma folha (Commons Wikipedia).

A circulação é classificada em vias que atravessam, vias que distribuem e vias locais. As que atravessam e as que distribuem definem o contorno de setores com diferentes tamanhos e formas, conforme indica o diagrama da figura 19, onde se esquematizam os corredores - faixas de uso diferenciado por estarem voltadas para a circulação principal - e a subárea que ocupa o miolo do setor. Vários setores em conjunto tem uma configuração nuclear que parece com as formações da natureza. Como uma folha, mas as duas formações têm características diferentes. Basta lembrar que a cidade se forma sobre um solo irregular e a folha cresce no ar sem nenhum obstáculo, o que permite sua estrutura ser regular. Pela micrografia (Figura 19) se pode verificar que na folha há um elemento repetitivo que define setores e na cidade os setores são variados em tamanho e forma. Finalmente, me aproximei do conceito que se consolidou através dos procedimentos dos corredores e subáreas, decorrente de se estudar as partes do edifício e da cidade, uma simples lição tomada de observar os tipos de edifícios e dos tecidos urbanos tradicionais.

\section{REFERÊNCIAS}

ALEXANDER, C. CHERMAYEFF, S. Community and privacy: toward a new architecture of humanism. London: Doubleday, 1963,

ALEXANDER, C. Silverstein, M. Angel, S. Ishigawa, S Abrams, D. The Oregon Experiment. New York. Oxford University Press, 1975.

BARNETT, J. Urban design as public policy. New York. McGraw-Hill. 1974.

FICHER, S; BATISTA, G. N. Guia Arquitetura de Arquitetura, Brasília. p. 165, Empresa das Artes, 2000.

HABRAKEN, N. J., Supports, an alternative to mass housing, London, Architectural Press, 1972.

HABRAKEN, N. J. The structure of the ordinary, form and control in the built environment. Cambridge, MA: The M.I.T Press. 2.000 .

LYNCH, K. (1960) A imagem da cidade. São Paulo, Martins Fontes, 2006

LYNCH, K. Site Planning. Cambridge, MA. The M.I.T. Press, 1962.

MACEDO, A.C., Corredores e subáreas, como estudar a forma e projetar a cidade. Tupã, ANAP, 2021, e-book, https://www.amigosdanatureza.org.br/biblioteca/livros/item/cod/230.

MACEDO, A. C. Projeto urbano como arquitetura, paisagismo e implementação, in Desenho Urbano, Pasquotto, G, B; Gulinelli E.L.(Orgs), Capítulo 1, p.13-28. São Paulo, Editor ANAP, e-book. 2019.

MOHOLY-NAGY, Sibyl. Matrix of man, an illustrated history of urban environment. Londres, Frederick A. Praeger Publishers, 1968

NEUTRA, R. J., (1954) Survival through design. England. Oxford University Press, 1969.

NOTA DO EDITOR (*): O conteúdo do artigo e as imagens nele publicadas são de responsabilidade do(s) autor(es). 